EXTENDED REPORT

\title{
Albumin as a tear supplement in the treatment of severe dry eye
}

\author{
S Shimmura, R Ueno, Y Matsumoto, E Goto, A Higuchi, J Shimazaki, K Tsubota
}

Br J Ophthalmol 2003;87:1279-1283

See end of article for authors' affiliations

Correspondence to: Shigeto Shimmura, $M D$ Department of Ophthalmology, Tokyo Dental College, 5-11-13 Sugano, Ichikawa, Chiba 272-0824, Japan; shimmura@tdc.ac.jp

Accepted for publication 20 February 2003

\begin{abstract}
Aim: To determine the efficacy of using albumin tear supplements in the treatment of ocular surface disorders as a substitute for serum eye drops.

Methods: The effects of albumin on the viability of serum deprived conjunctival cell were observed in vitro. The ability for albumin to compensate for serum was demonstrated by measuring the activity of the apoptosis related enzyme, caspase-3. In an animal study, corneal erosions were inflicted in 40 Japanese white rabbits. Rabbits were treated with $5 \%$ or $10 \%$ solutions of human albumin, and the decrease in epithelial defect size was compared with saline control and $0.3 \%$ sodium hyaluronate. A clinical case series trial of $5 \%$ albumin drops was conducted in nine patients with Sïogren's syndrome with severe dry eye.

Results: The addition of albumin to serum deprived conjunctival cells inhibited caspase activity and increased cell viability, showing that albumin can compensate for some of the physiological properties of serum. Corneal erosions in rabbits healed significantly faster $(p<0.05)$ in eyes treated with $10 \%$ albumin compared with control and sodium hyaluronate. Patients with Siögren's syndrome used albumin drops showed statistically significant improvement in fluorescein and rose bengal scores, but not in tear break up time and subjective symptoms. No adverse effects of albumin were observed during the study.

Conclusions: The use of albumin as a protein supplement in artificial tear solutions is a viable approach in the treatment of ocular surface disorders associated with tear deficiency.
\end{abstract}

D amage to the ocular surface in Sjögren's syndrome (SS) is due to a severe form of dry eye that is often resistant to many of the treatments currently available. Conjunctival involvement is greater with SS dry eye than with non-SS dry eye, with the characteristic loss of goblet cells and squamous metaplasia of the epithelium demonstrated by impression cytology. ${ }^{1}$ Lymphocytes infiltrating the lacrimal gland destroy the acinar structure to the extent that secretion of tears is severely decreased, even under nasal stimulation. ${ }^{23}$ It is now believed that these changes to the ocular surface in SS are not only caused by desiccation, but are further exacerbated by the loss of many crucial components in tears such as growth factors and vitamins. ${ }^{4-7}$

Fox et al were the first to report the possibility of using serum as a source of tear replacement in severe dry eye associated with SS. ${ }^{8}$ Autologous serum drops were reported to be effective in another clinical trial, ${ }^{9}$ as well as for persistent epithelial defects ${ }^{10}$ and conjunctival lesions in superior limbic keratoconjunctivitis. ${ }^{11}$ These reports hypothesised that many of the physiological components found in serum act as a replacement for the tear components lost in severe dry eye. Autologous serum drops are now a crucial adjuvant in ocular surface reconstruction of ocular surface disease such as Stevens-Johnson syndrome, ocular cicatricial pemphigoid, and chemical/thermal burns. ${ }^{12}$

However, the use of serum as a tear replacement is not without problems, especially when handling serum from patients with transmissible disease such as HIV, hepatitis B, hepatitis $\mathrm{C}$, and prion disease. The logical solution to this would be to develop artificial tear solutions that contain some of the key components of tears, ${ }^{13}$ including tear proteins. Although tears contain proteins with specific functions such as lactoferrin ${ }^{14}$ and immunoglobulins, ${ }^{15}$ a substantial quantity of other non-defined proteins in the pre-albumin and albumin fractions are also found. We hypothesised that some of the therapeutic effects of serum drops can be reproduced by artificial protein solutions applied to the ocular surface. Human albumin was chosen as a protein source since it is widely used in infusion therapy. In the present study, the effect of albumin on cell viability was first observed in vitro, using a caspase enzyme assay in serum deprived conjunctival epithelial cells. An animal experiment using rabbits was done with epithelial migration rate as a parameter for the effect of albumin application. We then undertook a pilot case series enrolling nine SS patients suffering from severe dry eye after the study was approved by the ethics board of the institution.

\section{METHODS}

\section{Caspase assay}

A human conjunctival epithelial cell line (CCL, American Type Culture Condition, Manassas, VA, USA) was used for the enzyme assay. Cells were cultured in $75 \mathrm{~cm}^{2}$ culture flasks with M119 medium (Gibco BRL Life Technologies, Rockville, MD, USA) containing $10 \%$ fetal calf serum (FCS) until $70-80 \%$ confluence. FCS $(+)$ medium was then removed, and cells were culture for 24 hours in either serum free M1 19 media with or without human albumin $(0.1 \mathrm{mg} / \mathrm{ml}$, Midori Juji Inc, Tokyo, Japan). Control cells had medium replaced with fresh M119 containing serum at the same time. Cells were harvested with a trypsin/EDTA solution and suspended in $10 \mathrm{ml}$ of ice cold PBS. Following centrifugation, cells were washed twice with phosphate buffered saline (PBS) and a total count of cells was calculated. Cells were lysed in lysis buffer containing $50 \mathrm{mM}$ HEPES, 1 mM DTT, 0.1 mM EDTA, $0.1 \%$ CHAPS and $1 \mathrm{mM}$ PMSF ( $\mathrm{pH} 7.4$ ) at a concentration of $5 \times 10^{6}$ cells $\times 10^{6} / \mathrm{l}$. Cell extract was obtained from the supernatant of lysis buffer after centrifugation at $10000 \mathrm{~g}$ for 10 minutes. Protein concentration of each sample was measured before caspase assays.

Cell extract $(10 \mu \mathrm{l})$ was diluted with $80 \mu \mathrm{l}$ of assay buffer (50 mM HEPES, $100 \mathrm{mM} \mathrm{NaCl}, 10$ mM DTT, I mM EDTA, 
$10 \%$ glycerol, $0.1 \%$ CHAPS, pH 7.4). Samples were placed in 96 well plates, and incubated with the caspase- 3 substrate, DEVD-AFC (0.1 mM final concentration, Enzyme System Products, Livermore, CA, USA) for 1 hour. DEVD-AFC gains fluorescence after being enzymatically cleaved by caspase- 3 present in the cell lysis samples. Fluorescence was measured using a fluorophotometer (F3000, Hitachi, Tokyo, Japan) with excitation at $400 \mathrm{~nm}$ and emission at $505 \mathrm{~nm}$. Data were presented as caspase-3 activity plotted against a standardisation curve using the fluorescent product, AFC. The experiment was repeated in triplicate ( $\mathrm{n}=6$ each). Statistical analysis was done using the Dunnett's test.

\section{Animal study}

Eighteen Japanese albino rabbits (mean body weight $2.36 \mathrm{~kg}$ ) were reared in cages for 17 days before experiments. The right eye of each rabbit was used as the treated eye. Animals were divided into four groups $(\mathrm{n}=6$ each), and assigned to saline control, 5\% recombinant albumin drops, $10 \%$ recombinant albumin, or $0.3 \%$ sodium hyaluronate (Hyalein Mini, Santen Pharmaceuticals, Osaka, Japan). Rabbits were anaesthetised with Nembutal, and central corneal abrasions were made using $7.0 \mathrm{~mm}$ diameter filter papers soaked with $7 \mu \mathrm{l}$ of $\mathrm{n}$-heptanol. The paper filter was applied to the cornea for 1 minute, and remaining epithelium was washed with sterile saline. The cornea was stained with fluorescein, and the defect size was measured using a planimeter at 6 hour intervals starting immediately following abrasion $(0,6,12,24,30,36,48,54,60$, and 72 hours $)$. The area of the wound at each time interval was normalised with initial wound size designated as $100 \%$. The total time required for wound closure was also recorded as the recovery time.

Test substances were applied by micropipette ( $30 \mu \mathrm{l})$, every 2 hours, six times a day until complete wound healing was achieved.

\section{Clinical case series}

One male and eight female patients with Sjögren's syndrome (SS) were enrolled in a pilot study using 5\% albumin eye drops. The study was authorised by the ethics review board of Tokyo Dental College, under condition that all lot numbers of albumin samples be recorded for traceability of serum source. Patients were told of the potential benefits and possible side effects involved with using serum albumin as tear supplements. This included the minor risk of contamination with unknown viral or prion disease. Written informed consent was obtained from each patient before participation in the study.

The diagnosis of SS was based on the criteria proposed by Fox et al. ${ }^{16}$ Rose bengal and fluorescein staining, tear break up time (BUT), Schirmer test values and subjective symptom scores were the main parameters examined. Although all patients suffered bilateral dry eye, only the right eye was used for statistical analysis. Rose bengal score (full score 9) and fluorescein score (full score 9) were calculated as previously described. ${ }^{13}$ Overall subjective symptoms was graded by a "face score," consisting of a questionnaire with nine cartoon characters expressing different levels of discomfort. ${ }^{17}$ Patients were instructed to apply albumin six times a day, in addition to ongoing medication of artificial tears and lubricants. Two patients (patients 1 and 3) were using autologous serum eye drops at the point of enrolment, which was discontinued and replaced with albumin drops. Patient demographics are listed in Table 1.

Slit lamp examination and staining patterns were analysed at 2 weeks and 4 weeks, and the change in scores was statistically analysed by the Wilcoxon's signed ranks test. Statistical software used was Stat View version 5 for the Macintosh (SAS Institute Inc, Cary, NC, USA).

\section{RESULTS}

\section{Caspase assay}

Caspase- 3 activity was measured in subconfluent conjunctival epithelial cells that were either serum deprived, or cultured with $1 \mathrm{mg} / \mathrm{ml}$ albumin in M199 medium (Fig 1). Caspase activity shows a threefold increase 24 hours after serum withdrawal (1.00 (SD 0.07$) \mathrm{nmol} / \mathrm{h} / \mathrm{mg}$ protein). When human albumin was added to the Ml19 medium instead of FCS, the increase in caspase-3 activity was suppressed to $0.75(0.13) \mathrm{nmol} / \mathrm{h} / \mathrm{mg}$ protein $(\mathrm{p}<0.05)$. This suppressive effect was observed without the addition of any growth factors or vitamins contained in serum or commercially available pituitary extract culture supplements.

Since prolonged culture of epithelial cells alone causes apoptosis, a control group of cells were also observed for the same time course. Control cells were treated with fresh M119

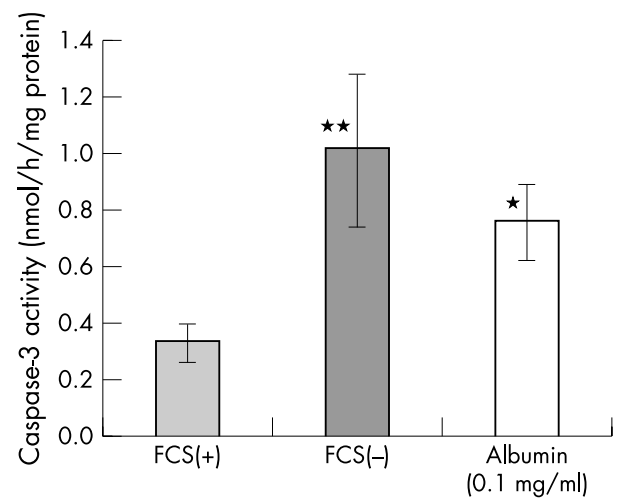

Figure 1 Caspase-3 activity in conjunctival epithelial cells culture with (FCS(+)) and without (FCS(-)) $10 \%$ fetal calf serum. A threefold increase in caspase- 3 activity is observed 24 hours after serum removal. The addition of albumin in medium significantly suppressed caspase activity $\left({ }^{*} p<0.05 \vee F C S(-)\right),{ }^{* *} p<0.05 \vee F C S(+), n=6$.

Table 1 Patient demographics

\begin{tabular}{|c|c|c|c|c|c|c|c|}
\hline Patient No & Sex & Age (years) & Schirmer test (mm) & Rose bengal score & Fluorescein score & BUT (s) & Previous medication \\
\hline 1 & $\mathrm{~F}$ & 63 & 5 & 7 & 5 & 2 & $\mathrm{HA}, \mathrm{AT}, 0.1 \% \mathrm{FL}$, serum \\
\hline 2 & $\mathrm{~F}$ & 68 & 1 & 6 & 3 & 3 & $\mathrm{HA}, \mathrm{AT}$ \\
\hline 3 & $M$ & 63 & 2 & 4 & 6 & 4 & $\mathrm{HA}, \mathrm{AT}$, serum \\
\hline 4 & $\mathrm{~F}$ & 77 & 2 & 5 & 6 & 3 & AT, $0.1 \% \mathrm{FL}$ \\
\hline 5 & $\mathrm{~F}$ & 65 & 3 & 3 & 3 & 2 & AT \\
\hline 6 & $\mathrm{~F}$ & 57 & 4 & 4 & 4 & 3 & $\mathrm{HA}, \mathrm{AT}$ \\
\hline 7 & $\mathrm{~F}$ & 47 & 4 & 4 & 6 & 2 & $\mathrm{HA}, \mathrm{AT}$ \\
\hline 8 & $\mathrm{~F}$ & 54 & 2 & 5 & 5 & 1 & AT \\
\hline 9 & $\mathrm{~F}$ & 46 & 2 & 2 & 9 & 4 & AT, $0.1 \% \mathrm{FL}$ \\
\hline
\end{tabular}

$\mathrm{HA}=$ sodium hyaluronate drops, $\mathrm{AT}=$ aqueous artificial tears, $\mathrm{FL}=$ fluorometholone . 
Table 2 Time course of relative epithelial defect area (\%)

\begin{tabular}{lllll}
\hline Time (hours) & Saline & Alb 5\% & Alb 10\% & HYA 0.3\% \\
\hline 0 & $100.0(0.0)$ & $100.0(0.0)$ & $100.0(0.0)$ & $100.0(0.0)$ \\
6 & $112.5(2.2)$ & $100.0(2.2)^{* *}$ & $103.5(1.7)^{*}$ & $99.1(3.0)^{* *}$ \\
12 & $90.0(0.6)$ & $85.4(2.8)$ & $85.8(1.6)^{*}$ & $80.3(1.9)$ \\
24 & $52.1(0.6)$ & $52.1(2.6)$ & $48.7(1.3)^{*}$ & $51.9(2.2)$ \\
30 & $32.8(1.4)$ & $34.6(3.7)$ & $28.3(1.6)^{*}$ & $37.5(1.6)^{*}$ \\
36 & $17.5(1.7)$ & $21.7(4.2)$ & $14.2(1.1)$ & $21.5(0.7)$ \\
48 & $2.0(1.0)$ & $6.0(3.3)$ & $0.0(0.0)$ & $4.0(0.4)$ \\
54 & $0.6(0.4)$ & $3.3(2.1)$ & $0.0(0.0)$ & $0.1(0.1)$ \\
60 & $0.0(0.0)$ & $1.7(1.1)$ & $0.0(0.0)$ & $0.0(0.0)$ \\
72 & $0.0(0.0)$ & $0.0(0.0)$ & $0.0(0.0)$ & $0.0(0.0)$ \\
\hline
\end{tabular}

$\mathrm{Alb}=$ albumin, $\mathrm{HYA}=$ sodium hyaluronate values expressed as mean (SEM), ${ }^{* *} \mathrm{p}<0.01,{ }^{*} \mathrm{p}<0.05 \mathrm{v}$ saline (Student's $t$ test).

media containing $10 \%$ FCS at the same time point as the experiment group of cells receiving serum free media and albumin. Control cells showed low levels of caspase-3 activity (0.33 (0.07) $\mathrm{nmol} / \mathrm{h} / \mathrm{mg}$ protein), demonstrating that culture conditions alone were not the cause of cell apoptosis observed with serum deprivation.

\section{Animal study}

Two concentrations of albumin (5\% and $10 \%)$ eye drops were compared with saline control in a wound healing model in Japanese white rabbits. Sodium hyaluronate (HA) drops were also included in the study as a high viscosity control. At 6 hours following abrasion of the corneal epithelium, both albumin solutions and HA drops showed a statistically significant recovery of wound size (Table 2 ). The intergroup difference diminished during the subsequent time course of 6 hour intervals, for up to 30 hours. When the recovery ratio (percentage of completely healed corneas/total number of eyes) was calculated at 48 hours, $100 \%$ of eyes receiving $10 \%$ albumin drops had healed, which was significantly greater than saline control (Table 3, p $<0.05, \chi^{2}$ test). Surprisingly, none of the eyes receiving HA drops had healed completely after 48 hours.

All animals were observed daily by slit lamp examination to observe for clinical signs of intraocular inflammation, infiltration of inflammatory cells within the cornea, and hyperaemia/chemosis of the conjunctiva. No adverse effects of albumin drops were observed in any of the animals at any time during the course of the study.

\section{Clinical case series}

Compliance with the study protocol was excellent in all nine patients enrolled. All patients applied albumin drops as instructed without complaints or side effects. Of all the objective parameters and subjective symptoms analysed, fluorescein staining, rose bengal staining, BUT and symptomatic face score showed a statistically significant improvement over the 4 week study period (Table 4 ). The improvement was compared with pretreatment values, when patients had already been treated with conventional dry eye therapy. Slit

Table 3 Effect of albumin on wound healing in rabbits

\begin{tabular}{llll}
\hline & No of eyes & $\begin{array}{l}\text { Completely healed } \\
\text { eyest }\end{array}$ & Ratio \\
\hline Saline & 6 & 3 & $50 \%$ \\
Alb 5\% & 6 & 2 & $33 \%$ \\
Alb 10\% & 6 & 6 & $100 \% * * *$ \\
HYA 0.3\% & 6 & 0 & $0 \% *$ \\
\hline
\end{tabular}

$\mathrm{Alb}=$ albumin, $\mathrm{HYA}=$ sodium hyaluronate. ${ }^{*} \mathrm{p}<0.05 v$ saline, ${ }^{* *} \mathrm{p}<0.05 v$ HYA $\left(\chi^{2}\right.$ test).

†The number of completely healed eyes after 48 hours. lamp photographs of patients 5 and 9 are shown in Figures 2 and 3 respectively, with both fluorescein and rose bengal stains improving after applying albumin drops for 2 weeks.

\section{DISCUSSION}

Albumin is a soluble $66.5 \mathrm{kD}$ monomeric protein that accounts for approximately half of the total protein content in serum. The major role of albumin in serum is as a carrier of various insoluble components such as free fatty acids and hormones such as thyroxine and corticosteroids. ${ }^{18}$ All of these functions can also apply to tear albumin, since the tear film contains many of the physiologically active components found in serum. A similar role of binding hydrophobic molecules was postulated as the role of apolipoprotein D secreted by the lacrimal gland. ${ }^{19}$ These proteins may be involved in the turnover of tear components and topically applied drugs.

Albumin is not a foreign protein to the ocular surface, and a concentration gradient is observed with higher concentrations found within the anterior third of the corneal stroma. ${ }^{20}$ Albumin also diffuses out of dilated conjunctival vessels into the tear film, the concentration of which increases during eye closure $^{21}$ and wounding. ${ }^{22}$ Tear albumin, therefore, can be considered a non-specific marker of ocular surface integrity. There are no reports to date that demonstrate any physiological role for albumin in tears. However, other proteins that diffuse out of conjunctival vessels such as fibronectin, ${ }^{21}{ }^{23}$ are associated with functional roles. Therefore, the significance of albumin in tears should not be ruled out simply because of the ubiquitous nature of this globular protein.

Although the data presented in the present study are limited, it is the first attempt to our knowledge to demonstrate the effects of albumin tear supplements in the treatment of ocular surface disorders. We have shown in vitro that the addition of albumin can compensate for some of the cell viability lost through the process of apoptosis. Although caspase- 3 activity was the only objective parameter measured, cells incubated with albumin showed less degree of cell detachment than serum deprived cells. There was also no evidence of cell viability loss through the process as a result of possible toxicity of albumin in the cell medium.

Table 4 Change in clinical scores after 2 and 4 weeks

\begin{tabular}{lllll}
\hline Scores & $\mathbf{0}$ weeks & $\mathbf{2}$ weeks & $\mathbf{4}$ weeks & $\mathbf{p ~ V a l u e ~}$ \\
\hline Fluorescein & $5.1(2.0)$ & $2.2(1.9)$ & $1.8(1.1)$ & 0.01 \\
Bengal & $4.7(2.1)$ & $3.2(2.0)$ & $3.0(2.2)$ & 0.049 \\
BUT & $2.7(1.0)$ & $5.2(2.9)$ & $5.2(2.2)$ & 0.02 \\
Face score & $7.5(1.9)$ & $6.5(1.9)$ & $5.6(2.0)$ & 0.03
\end{tabular}

Statistical analysis by Wilcoxon signs rank test comparing data at 0 weeks with 4 weeks. 

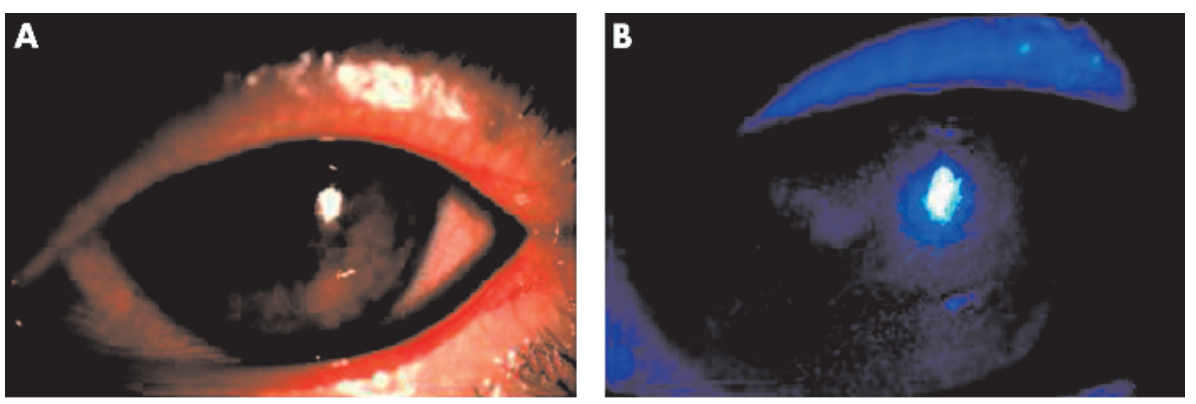

Figure 2 Pretrial slit lamp view for patient 5 with rose bengal (A) and fluorescein stain (B). Both stains improved after the first 2 weeks of albumin application (C) (D).
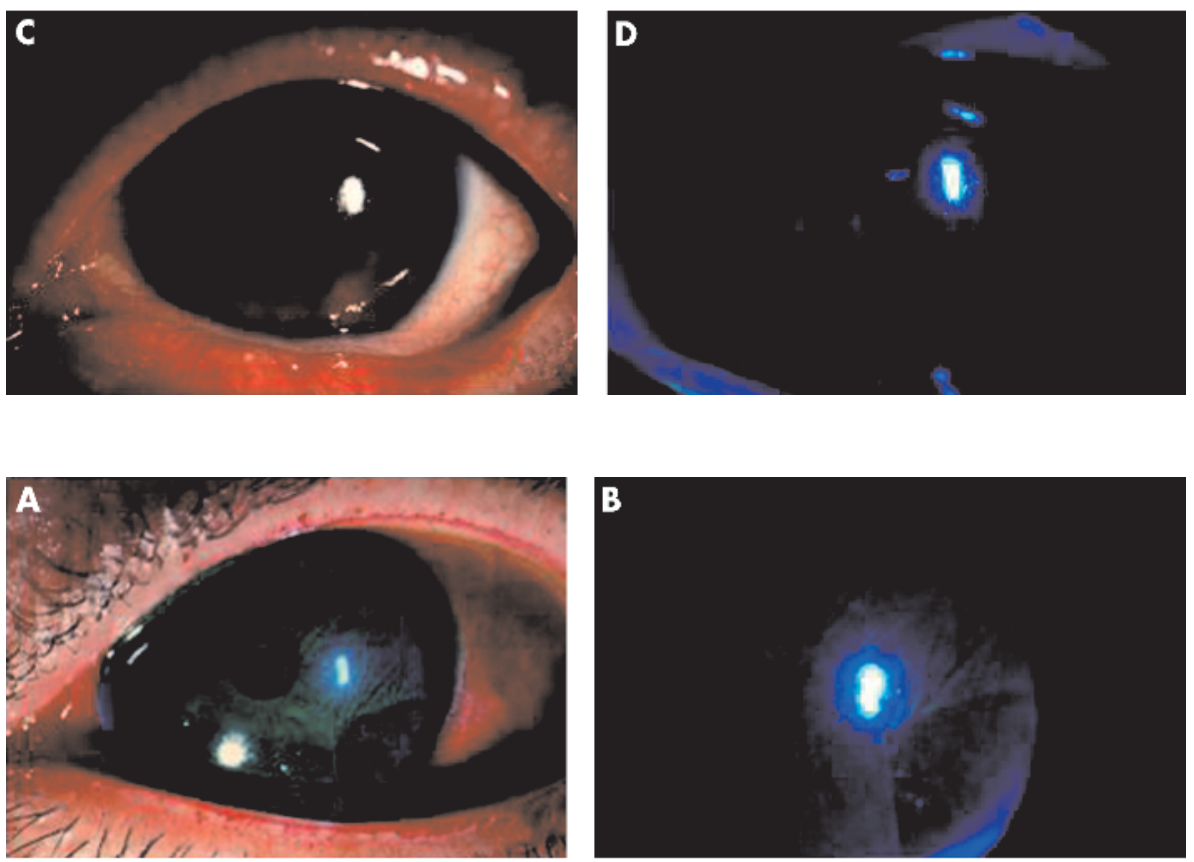

Figure 3 Pretrial slit lamp view for patient 9 with rose bengal $(A)$ and fluorescein stain (B). Both stains improved after the first 2 weeks of albumin application (C) (D).
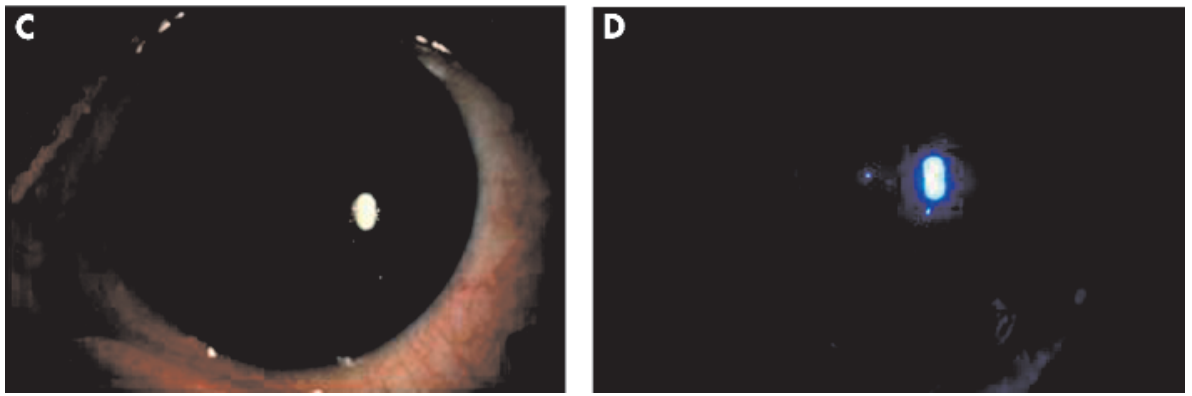

The nature of albumin as a water soluble protein alone may be a factor in stabilising the preocular tear film. Results of the clinical pilot study show that staining scores significantly improved over the 4 week study period. Of special interest is rose bengal, which is said to stain areas with poor protection by the preocular tear film. ${ }^{24}$ This staining pattern can be blocked by the addition of lactoferrin, transferrin, as well as albumin. ${ }^{25}$ Topical albumin may therefore compensate for the lack of soluble mucin in patients with Sjögren's syndrome. Our data also show that fluorescein staining also improves with topical albumin application. Unlike rose bengal, fluorescein is not blocked by albumin, and therefore the data can be interpreted as an improvement in cell to cell junctions of the cornea epithelium. Other possible therapeutic effects exerted by albumin may include anti-inflammatory properties $^{26}$ or antioxidant effects. ${ }^{27}$ There is also the possibility that albumin conjugates with other topical medication allowing for a longer retention time on the ocular surface. These are issues that we plan to pursue both in vivo and in vitro.

The animal study revealed accelerated wound healing in eyes receiving albumin drops. Although the experiment is not a real model of dry eye, the experimental design was chosen since it was the only feasible model for corneal trauma that was both consistent and reproducible. The HA group was included as a high viscosity control, and interestingly, this group showed a delay in epithelialisation towards the end of the wound healing process. The data seem to show that the effects exerted by albumin are not only the result of increased viscosity.

A large scale study is awaited for the use of albumin drops in other ocular surface disorders in view of the limited nature of this current study. Although the clinical pilot study was limited to Sjögren-type dry eye patients, the results of the animal study show that albumin may also benefit patients with persistent epithelial defects. The ideal concentration for 
albumin formulas also need to be determined, since the clinical trial of this study concentrated on the $5 \%$ solution, a concentration which was chosen on the basis that this was within the range of protein contents in tears.

Although no adverse effects were observed during the clinical study, a minute risk of transmissible viral and prion disease cannot be ruled out. Given the promising data presented in this pilot study, an extended clinical trial is worth considering. In view of the problems associated with blood products, the mass production of albumin by bioengineering techniques should be considered. The feasibility of developing such a product has already been proved by many of the insulin products available for diabetics. The need for albumin in other areas of medicine should also be a driving force in the development of bioengineered albumin eye drops.

\section{Authors' affiliations \\ S Shimmura, Y Matsumoto, E Goto, A Higuchi, J Shimazaki, K Tsubota, Department of Ophthalmology, Tokyo Dental College, Chiba, Japan R Ueno, R-Tech Ueno Ltd, Japan}

Proprietary interests: Patent pending by K Tsubota supported by R-Tech Ueno Ltd.

\section{REFERENCES}

1 Pflugfelder SC, Huang AJ, Feuer W, et al. Conjunctival cytologic features of primary Sjogren's syndrome. Ophthalmology 1990;97:985-91.

2 Tsubota K. The importance of the Schirmer test with nasal stimulation. Am J Ophthalmol 1991;111:106-8.

3 Xu KP, Katagiri S, Takeuchi T, et al. Biopsy of labial salivary glands and lacrimal glands in the diagnosis of Sjogren's syndrome. J Rheumatol 1996;23:76-82.

4 Ubels JL, Foley KM, Rismondo V. Retinol secretion by the lacrimal gland. Invest Ophthalmol Vis Sci 1986:27:1261-8.

5 Ohashi Y, Motokura M, Kinoshita Y, et al. Presence of epidermal growth factor in human tears. Invest Ophthalmol Vis Sci 1989;30:1879-82.

6 Wilson SE. Lacrimal gland epidermal growth factor production and the ocular surface. Am J Ophthalmol 1991;111:763-5.

7 Van Setten G, Schultz G. Transforming growth factor-alpha is a constant component of human tear fluid. Graefes Arch Clin Exp Ophthalmol 1994;232:523-6.
8 Fox RI, Chan R, Michelson JB, et al. Beneficial effect of artificial tears made with autologous serum in patients with keratoconjunctivitis sicca. Arthritis Rheum 1984;27:459-61.

9 Tsubota K, Goto E, Fujita $\mathrm{H}$, et al. Treatment of dry eye by autologus serum application in Sjogren's Syndrome. Br J Ophthalmol 1999;83:390-5.

10 Tsubota K, Goto E, Shimmura S, et al. Treatment of persistent corneal epithelial defect by autologous serum application. Ophthalmology 1999; 106:1984-9.

11 Goto E, Shimmura S, Shimazaki J, et al. Treatment of superior limbic keratoconjunctivitis by application of autologous serum. Cornea 2001;20:807-10.

12 Tsubota K, Satake Y, Kaido M, et al. Stem cell transplantation of corneal epithelium for the treatment of severe ocular surface disorders. New Engl J Med 1999;340:1697-703.

13 Shimmura S, Ono M, Shinozaki K, et al. Sodium hyaluronate eyedrops in the treatment of dry eyes. Br J Ophthalmol 1995;79:1007-11

14 Kijlstra A, Jeurissen SH, Koning KM. Lactoferrin levels in normal human tears. Br J Ophthalmol 1983;67:199-202.

15 Sen DK, Sarin GS. Immunoglobulin concentrations in human tears in ocular diseases. Br J Ophthalmol 1979;63:297-300.

16 Fox RI, Saito I. Criteria for diagnosis of Sjogren's syndrome. Rheum Dis Clin North Am 1994;20:391-407.

17 Toda I, Yagi Y, Hata S, et al. Excimer laser photorefractive keratectomy for patients with contact lens intolerance caused by dry eye. Br J Ophthalmol 1996;80:604-9.

18 Voet D, Voet J. Biochemistry, 2nd ed. New York: John Wiley, 1995.

19 Holzfeind P, Merschak P, Dieplinger H, et al. The human lacrimal gland synthesizes apolipoprotein D mRNA in addition to tear prealbumin mRNA both species encoding members of the lipocalin superfamily. Exp Eye Res 1995;61:495-500

20 Gong $\mathbf{H}$, Johnson $M, Y e W$, et al. The non-uniform distribution of albumin in human and bovine cornea. Exp Eye Res 1997;65:747-56.

21 Fukuda $M$, Fullard RJ. Willcox $M D$, et al. Fibronectin in the tear film. Invest Ophthalmol Vis Sci 1996;37:459-67.

22 Imayasu M, Moriyama T, Ohashi J, et al. A quantitative method for LDH, $\mathrm{MDH}$ and albumin levels in tears with ocular surface toxicity scored by Draize criteria in rabbit eyes. CLAO J 1992;18:260-6.

23 Fujikawa LS, Foster CS, Harrist TJ, et al. Fibronectin in healing rabbit corneal wounds. Lab Invest 1981;45:120-9.

24 Feenstra RP, Tseng SC. Comparison of fluorescein and rose bengal staining. Ophthalmology 1992;99:605-17.

25 Tseng SC, Zhang SH. Interaction between rose bengal and different protein components. Cornea 1995;14:427-35.

26 Zhang WJ, Frei B. Albumin selectively inhibits TNF alpha-induced expression of vascular cell adhesion molecule-1 in human aortic endothelial cells. Cardiovasc Res 2002;55:820-9.

27 Cantin AM, Paquette B, Richter M, et al. Albumin-mediated regulation of cellular glutathione and nuclear factor kappa B activation. Am J Respir Crit Care Med 2000;162:1539-46. 